\title{
Comparison of Effectiveness of Mobile App versus Conventional Educational Lectures on Oral Hygiene Knowledge and Behavior of High School Students in Saudi Arabia
}

This article was published in the following Dove Press journal:

Patient Preference and Adherence

\author{
Talal Zahid (D) \\ Rusha Alyafi \\ Noor Bantan \\ Rana Alzahrani \\ Eman Elfirt iD
}

Department of Periodontology, King Abdulaziz University, Jeddah, Saudi Arabia

Correspondence: Talal Zahid

Department of Periodontology, Faculty of Dentistry, King Abdulaziz University,

Jeddah, Saudi Arabia

Fax +966I26403316

Email Tzahid@kau.edu.sa
Objective: This study aimed to evaluate the impact of two different oral health education approaches, a mobile application (the Brush DJ app) and conventional educational lectures, on the oral hygiene knowledge and behavior of high school children.

Methods: The research was a cross-sectional study of 271 students from two public schools in Jeddah City, Saudi Arabia. An eighteen-item questionnaire was used for this purpose. Those who completed the baseline questionnaire were allocated to one of two groups: (1) mobile application and (2) educational lecture. A follow-up survey was later conducted at three months, which repeated eight of the eighteen questions asked in the baseline survey. The change in oral hygiene attitude and behaviors was compared across both groups.

Results: The Brush DJ app was found to be equally effective compared to educational lectures in changing oral health knowledge, attitude and behavior. Both groups showed significant improvements in almost all aspects of oral health, except for the frequency and duration of tooth brushing in the app group. There was no change in twice daily tooth brushing of app users, and less than $40 \%$ reported brushing their teeth for 2 minutes. A statistically significant change, however, was noted among lecture group participants in these two areas of oral hygiene routine. The app was also found to be more difficult in usability than educational lectures $(\mathrm{p}=0.037)$.

Conclusion: The Brush DJ app may be a valuable tool to improve oral health knowledge, attitude and behavior. However, the app needs some improvements. The content and features of the app need to be structured in a way that it allows for personalization and is more interactive, practical and user-friendly.

Keywords: oral health, oral health education, oral hygiene behavior, mobile application

\section{Introduction}

Oral diseases are major public health problems of considerable social and economic burden, owing to their high prevalence. According to the Global Burden of Disease Study 2016, about half (50\%) of the world's population is affected by oral diseases. ${ }^{1}$ Two oral conditions have been reported to account for most of the global oral health burdens: tooth decay (dental caries or cavities) and periodontal (gum) disease. Other oral conditions that commonly impact the overall well-being and quality of life include dental trauma, oral cancer, tooth wear (dental erosion, attrition and abrasion), edentulism, cleft lip and palate and oral manifestations of HIV. ${ }^{2}$ 
On a global scale, tooth decay of permanent teeth was found to be the most prevalent of all diseases and periodontal disease was the 11 th most prevalent condition. ${ }^{1}$ Statically, however, the scenario is far worse for underprivileged people living in developed and developing countries. In most industrialized countries, tooth decay has been reported to affect around $60-90 \%$ of schoolchildren as well as adults. ${ }^{3}$ Notable causes for the high prevalence of dental caries and periodontal diseases are poor oral hygiene, inadequate fluoride exposure and tobacco use.

The development of dental caries in the oral cavity can be substantially reduced by ensuring a constant low-level exposure to fluoride. This can be achieved by drinking fluoridated water, using a fluoride-containing toothpaste (1000 to $1500 \mathrm{ppm}$ ) or applying a topical fluoride gel. ${ }^{3,4}$ On the other hand, the prevention of periodontal diseases can be largely achieved by maintaining proper oral hygiene such as daily brushing and flossing. Hence, most clinicians now suggest twice-daily tooth brushing with an antimicrobial toothpaste containing fluoride to prevent tooth decay and gum diseases. ${ }^{5}$ However, there is also a need to educate people concerning the benefits of healthy oral habits to maintain good oral hygiene.

Proper knowledge and awareness related to oral health are essential for developing healthy oral hygiene behaviors. This has been demonstrated in earlier studies, which reported a direct association between increased oral health knowledge and better dental care. ${ }^{6-10}$ Consequently, to effectively prevent and control the prevalence of oral health burdens, it is important to develop healthy oral habits at an early stage of life. ${ }^{11}$ Hence, school children are the ideal target population given the fact that healthy hygiene behaviors that stem from the school-age years usually carry over into adulthood. However, although a larger body of literature has been published in many countries to evaluate the oral health knowledge, attitudes, and behavior among students, to date little attention has been given to develop effective oral disease preventive programs for this key target group.

mHealth or mobile health is an emerging sub-segment of eHealth that involves the use of mobile communication and/or wearable devices to improve the practice of medicine and public health. ${ }^{12}$ Several recent studies including systematic reviews have suggested the use of mobile devices as an invaluable adjunct, which could help improve the oral hygiene compliance in different age groups. ${ }^{13-16}$ In addition, it has been shown that the use of mHealth with a conventional oral health education program is more effective in improving compliance among adolescent patients than verbal instructions of oral hygiene alone. ${ }^{17,18}$ To date, however, only a limited number of studies have been conducted to evaluate the quality and effectiveness of numerous mobile applications developed for improving oral hygiene behavior.

This study aimed to assess and compare the impact of two different approaches of oral health education, mobile application and educational lecture, on the oral hygiene knowledge and behavior of high school children.

\section{Materials and Methods Study Design}

The present study was designed as a quasi-experimental study. The baseline survey was done to assess the knowledge and attitude of high school students towards oral hygiene. A follow-up survey was later conducted at three months to determine whether there was any improvement in oral health knowledge, attitude and behavior. The study protocol was reviewed and approved by the Research Ethics Committee at the King Abdulaziz University. The survey was conducted from November 2018 to march 2019 , using a structured questionnaire that was developed after a thorough literature review. A small working group committee independently reviewed and validated it.

\section{Patient Selection}

Study participants were recruited from two public schools (a female Governmental school and a male high school) in Jeddah City, Saudi Arabia. The principals of the two schools were contacted, and the permission to visit and conduct the survey was obtained. Student participation was completely voluntary. All students who were willing to take part in the baseline and follow-up survey and owned a smartphone, tablet or other smart devices were included. The rationale of the study was explained to prospective students beforehand. Written informed consent was obtained from parents, guardians or caregivers of each participant before participation.

We performed an a-priori sample size (n) calculation of 264 subjects, considering the frequency and duration of toothbrushing as the main outcomes, fixing an absolute error (d) of $5 \%$ and at type $I$ error $\left(Z_{1-\alpha / 2}\right)$ of $5 \%$, and with an expected proportion (p) of $22 \%$ estimated from a pilot study. We recruited 7 subjects additionally to address loss to follow-up during the study. 


\section{The Questionnaire}

An eighteen-item questionnaire was used for the baseline survey. Questionnaires were distributed manually in randomly selected classes. Collected data included demographics as well as information related to oral hygiene knowledge, attitude, and behaviors. Participants who completed the initial survey (baseline) were allocated to one of two groups using simple randomization: (a) mobile application group and (b) education lecture group. The improvement in oral hygiene behavior was compared across both groups. Eight of the eighteen questions used in initial survey were repeated in the follow-up survey to assess the change in knowledge and attitudes towards oral hygiene. Additional questions were included in the followup survey only to assess the efficacy of the method used (application vs lecture).

\section{Intervention}

We used two different approaches of oral health education to determine the oral hygiene knowledge and behavior of high school children: (1) mHealth and (2) conventional dental education lectures. In this study, the mobile application used was the Brush DJ app (iOS version 4.1.6/ Android version 4.0.11, Ben Underwood). We selected this application for multiple reasons: it is free and user friendly, listed in the Apps Library of the National Health Service (NHS) UK, and reported to be a promising tool that motivates an evidence-based oral hygiene routine. ${ }^{19}$ Participants of the mobile app group were briefed about the various features of the app and how to install and use it. They were also instructed to use the app twice daily for three months. For the conventional education group, a 20minute lecture session on good oral hygiene practices was delivered using whiteboard, markers, presentation slides, as well as dental teeth models. A dental hygienist carried out the lecture session. Participants of both groups were also supplied with additional learning and/or instruction materials in form of handouts.

\section{Statistical Analysis}

Categorical variables were summarized as counts and percentages. Mean and standard deviation were used to summarize the distribution of age. Bar plots were used to visualize the responses to attitude and knowledge questions. Statistical significance was assessed using Chisquare test (or Chi-square test of independence where appropriate). The $\%$ of positive answers for each question was used as an indicator for the knowledge and attitude towards oral hygiene. McNemar's test was used to test whether the change in the \% of positive answers was significantly different between baseline and follow-up survey within each group. Hypothesis testing was performed at 0.05 level of significance.

\section{Results}

\section{Baseline Demographic Characteristics}

A total of 271 students completed the baseline survey questionnaire. Of these, 130 respondents were planned to be allocated to the mobile application group and 141 were to the educational lecture group for the follow-up survey. The baseline demographics and the oral health attitudes were not significantly different between the two groups [see Table 1]. Overall, the male to female ratio was comparable in the study cohort $(47.6 \%$ and $52.4 \%$, respectively). The mean age of the included participants was $16.6 \pm 0.96$ years.

\section{Oral Health Knowledge, Attitudes and Behaviors}

Figure 1 outlines the baseline knowledge, attitude and behavior towards oral health among study participants. Less than half of the study participants reported using mouthwash while only $3.3 \%$ used it correctly (ie, once per day every two weeks) and about $15 \%$ flossed their teeth regularly. When asked about the oral hygiene behaviors, $>50 \%$ of the population reported brushing their teeth twice a day, almost one-third reported using a toothpaste with fluoride and $<40 \%$ reported changing it every three months. Nearly $50 \%$ reported having knowledge about the best brushing technique while only $37.3 \%$ answered the correct duration for teeth brushing. The frequency of dental visits was largely on demand. Only $5.54 \%$ reported having a routine dental check-up (at every 6 months). Around $60 \%$ of the participants had awareness about the negative impact of poor oral hygiene and $76 \%$ were aware of the main causes of tooth staining.

\section{Follow-Up Survey Results}

Of the 271 students recruited in the baseline survey, 234 (86.3\%) responded to the follow-up questionnaire (114 in the app group and 120 in the educational lecture group). Eight questions from the baseline questionnaire were repeated in the follow-up survey. 
Table I Demographic Characteristics and Oral Health Attitudes of Participants

\begin{tabular}{|c|c|c|c|c|}
\hline & $\begin{array}{l}\text { [ALL] } \\
N=27 \text { I }\end{array}$ & $\begin{array}{l}\text { App } \\
N=130\end{array}$ & Lecture $\mathbf{N}=|4|$ & $\mathbf{p}^{*}$ \\
\hline Gender & & & & 0.072 \\
\hline Female & $142(52.4 \%)$ & $76(58.5 \%)$ & $66(46.8 \%)$ & \\
\hline Male & $129(47.6 \%)$ & $54(41.5 \%)$ & $75(53.2 \%)$ & \\
\hline Age & $16.6(0.96)$ & $16.5(0.85)$ & $16.7(1.05)$ & 0.328 \\
\hline Have you ever attended a lecture on dental health? & & & & 0.291 \\
\hline No & $110(40.6 \%)$ & $48(36.9 \%)$ & $62(44.0 \%)$ & \\
\hline Yes & $161(59.4 \%)$ & $82(63.1 \%)$ & $79(56.0 \%)$ & \\
\hline Are you interested in attending an event related to oral health? & & & & 0.694 \\
\hline No & $142(52.4 \%)$ & $66(50.8 \%)$ & $76(53.9 \%)$ & \\
\hline Yes & $129(47.6 \%)$ & $64(49.2 \%)$ & $65(46.1 \%)$ & \\
\hline Do you want to know the benefits of good oral hygiene? & & & & 0.433 \\
\hline No & $63(23.2 \%)$ & $27(20.8 \%)$ & $36(25.5 \%)$ & \\
\hline Yes & $208(76.8 \%)$ & $103(79.2 \%)$ & 105 (74.5\%) & \\
\hline
\end{tabular}

Note: *Statistical analysis was performed using Chi-square test of independence.

Responses to Questions Included Only in the Follow-Up Survey

Of the four questions added in the follow-up survey, no significant difference between the two groups was found in three responses [Table 2]. Overall, almost half of the study participants reported benefitting from the lecture/app to schedule their appointments, around $80 \%$ liked the way of teaching, and nearly $60 \%$ noticed a change in their teeth and gums after using the app/lecture. However, of the two interventions, participants in the app group encountered significantly more difficulties with their intervention compared to those who received the lectures $(p=0.037)$.

\section{Responses to Questions Specific to the Use of App/ Lecture}

Less than $40 \%$ of the participants in the app group reported brushing their teeth until the app music ended at 2 minutes, while more than $80 \%$ of those in the lecture group reported brushing their teeth for 2 minutes as instructed. Statistical comparison between the groups was

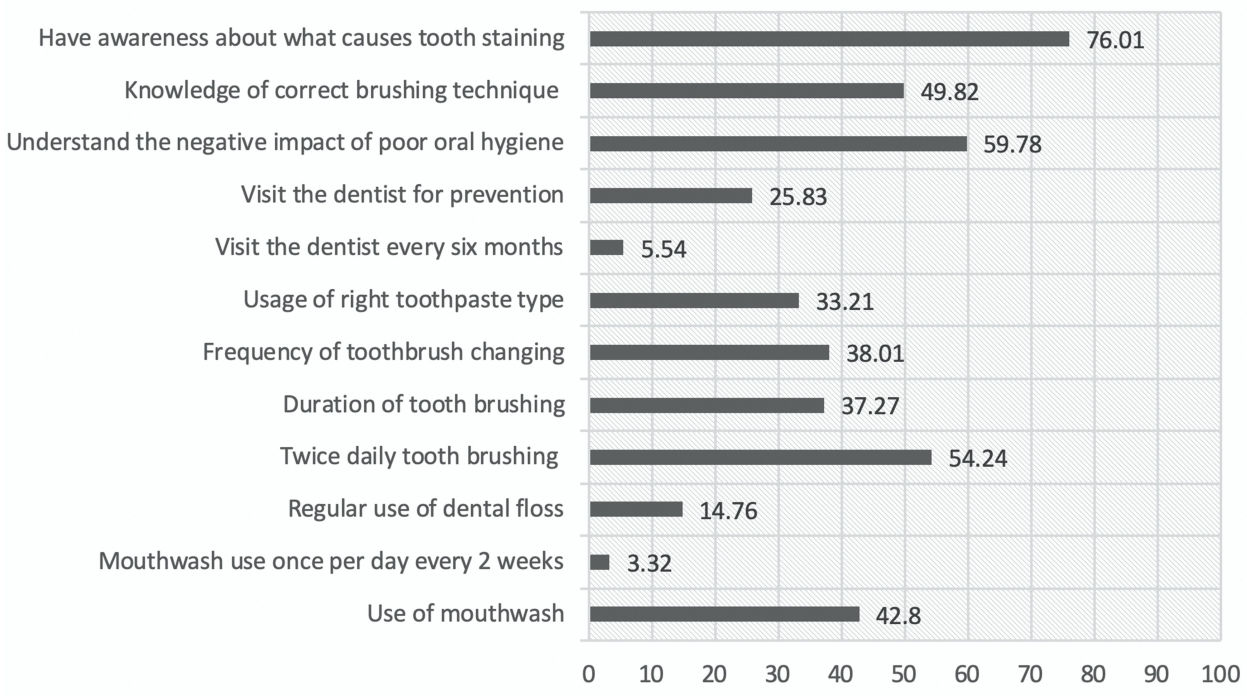

- Percentage (\%) of correct knowledge, attitude and behaviors in baseline responses 
Table 2 Responses to Questions Added in the Follow-Up Survey

\begin{tabular}{|c|c|c|c|c|}
\hline & $\begin{array}{l}{[A L L]} \\
N=234\end{array}$ & $\begin{array}{l}\text { App } \\
N=1 / 4\end{array}$ & $\begin{array}{l}\text { Lecture } \\
N=120\end{array}$ & $\mathbf{p}^{*}$ \\
\hline $\begin{array}{l}\text { Have you noticed any changes in teeth and gums after using the app/ } \\
\text { lecture? }\end{array}$ & & & & 0.539 \\
\hline No & $22(9.40 \%)$ & $10(8.77 \%)$ & $12(10.0 \%)$ & \\
\hline To some extent & $76(32.5 \%)$ & $41(36.0 \%)$ & $35(29.2 \%)$ & \\
\hline Yes & $136(58.1 \%)$ & $63(55.3 \%)$ & $73(60.8 \%)$ & \\
\hline Did you like the way of teaching in the app/lecture? & & & & 0.863 \\
\hline No & $17(7.26 \%)$ & $8(7.02 \%)$ & $9(7.50 \%)$ & \\
\hline To some extent & $32(13.7 \%)$ & 17 (14.9\%) & $15(12.5 \%)$ & \\
\hline Yes & I85 (79.1\%) & 89 (78.1\%) & $96(80.0 \%)$ & \\
\hline Have you encountered any difficulty in using the app/lecture? & & & & $0.037^{*}$ \\
\hline No & $203(86.8 \%)$ & $93(81.6 \%)$ & $110(91.7 \%)$ & \\
\hline Yes & $31(13.2 \%)$ & $21(18.4 \%)$ & $10(8.33 \%)$ & \\
\hline Did the app/lecture help you schedule a dentist's appointment? & & & & 0.449 \\
\hline No & $36(15.4 \%)$ & $21(18.4 \%)$ & $15(12.5 \%)$ & \\
\hline To some extent & $80(34.2 \%)$ & 37 (32.5\%) & $43(35.8 \%)$ & \\
\hline Yes & 118 (50.4\%) & $56(49.1 \%)$ & $62(51.7 \%)$ & \\
\hline
\end{tabular}

Note: *Statistical analysis was performed using Chi-square test of independence.

not performed due to the different number of choices across each group. More than $60 \%$ in the app group reported learning the right ways to clean their teeth or gum after watching videos in the app [Figure 2]. Similarly, around $66 \%$ mentioned taking advantage of the reminder icon in the app.

\section{Changes in Knowledge and Attitudes Towards Oral Hygiene}

Only eight questions were repeated in the follow-up survey.

Analysis of baseline and follow-up data revealed that the knowledge and attitude of participants towards oral health improved significantly in both groups for almost all aspects except for the frequency of tooth brushing in the app group [see Table 3]. In the follow-up responses, the use of mouthwash, floss and toothpaste with fluoride, the frequency of toothbrush changing at every 3 months, knowledge regarding the best brushing technique and awareness about the routine dental visit (at every 6 months) were increased among participants of both groups.

Post-test results showed that the percentage of correct answers was comparatively higher in the app group than the

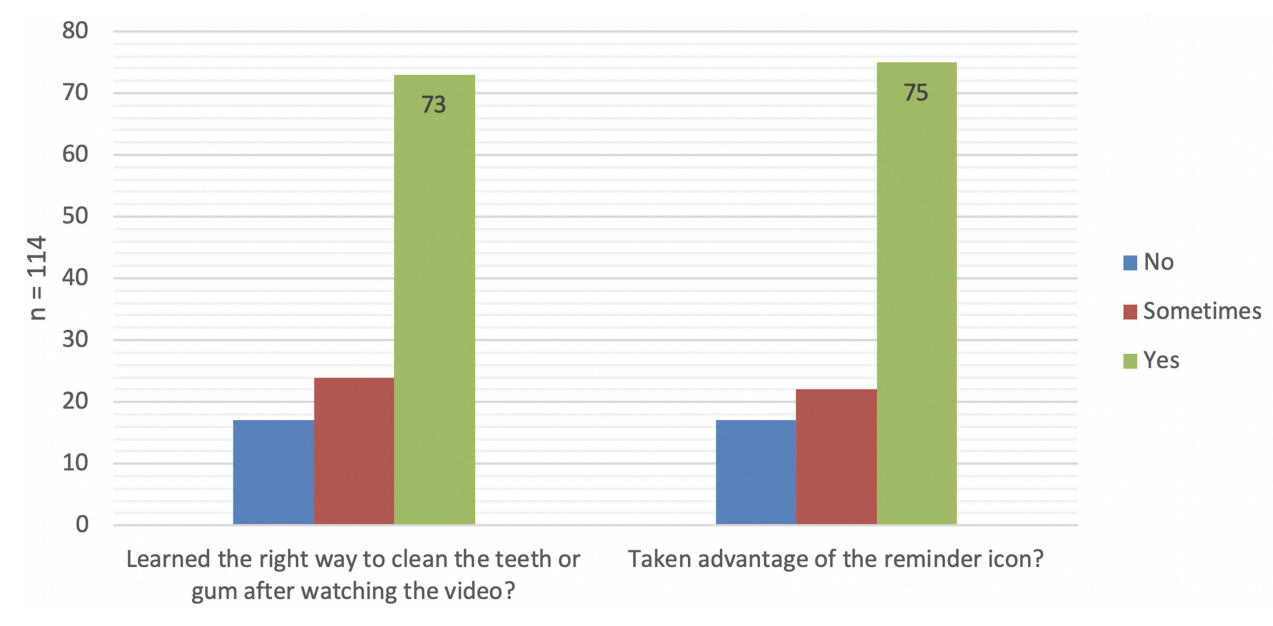

Figure 2 Perceived benefits from the two functions in the Brush DJ app. 
Table 3 Change in Knowledge and Attitudes Towards Oral Health Within the Groups

\begin{tabular}{|c|c|c|c|c|c|c|}
\hline & \multicolumn{3}{|c|}{ Mobile Application $(n=114)$} & \multicolumn{3}{|c|}{ Educational Lecture $(n=120)$} \\
\hline & Before & After & $p$ & Before & After & $p$ \\
\hline \multicolumn{7}{|l|}{ How often do you brush your teeth? } \\
\hline I rarely brush. & $8(7.02 \%)$ & $3(2.6 \%)$ & 0.87 & $17(14.2 \%)$ & $5(4.17 \%)$ & $<0.001^{*}$ \\
\hline Once daily irregularly & $13(11.4 \%)$ & $5(4.4 \%)$ & & $13(10.8 \%)$ & $13(10.8 \%)$ & \\
\hline Once daily regularly & $15(13.2 \%)$ & $30(26.3 \%)$ & & $27(22.5 \%)$ & $12(10.0 \%)$ & \\
\hline Twice daily regularly (A) & $78(68.4 \%)$ & $76(66.7 \%)$ & & $63(52.5 \%)$ & $90(75.0 \%)$ & \\
\hline \multicolumn{7}{|c|}{ How often do you change your toothbrush? } \\
\hline Every 3 months (A) & $53(46.5 \%)$ & $78(68.4 \%)$ & $<0.001 *$ & $40(33.3 \%)$ & $54(45.0 \%)$ & 0.08 \\
\hline Every 6 months & $31(27.2 \%)$ & $22(19.3 \%)$ & & $27(22.5 \%)$ & $40(33.3 \%)$ & \\
\hline After I year & $8(7.02 \%)$ & $8(7.02 \%)$ & & $10(8.33 \%)$ & $2(1.67 \%)$ & \\
\hline Till bristles fray & $22(19.3 \%)$ & $6(5.2 \%)$ & & $43(35.8 \%)$ & $24(20.0 \%)$ & \\
\hline \multicolumn{7}{|c|}{ Do you think you know how to brush your teeth properly? } \\
\hline No & $5(4.4 \%)$ & $2(1.75 \%)$ & $<0.001 *$ & $8(6.67 \%)$ & $2(1.67 \%)$ & $0.005 *$ \\
\hline To some extent & $62(54.4 \%)$ & $31(27.2 \%)$ & & $67(55.8 \%)$ & $50(41.7 \%)$ & \\
\hline Yes (A) & $47(41.2 \%)$ & 81 (7I.1\%) & & 45 (37.5\%) & $68(56.7 \%)$ & \\
\hline \multicolumn{7}{|c|}{ In your opinion, what tooth brushing technique would be best? } \\
\hline Horizontal movement & $15(13.2 \%)$ & $14(12.3 \%)$ & $0.035^{*}$ & $24(20.0 \%)$ & $12(10.0 \%)$ & $<0.001^{*}$ \\
\hline Vertical movement & $23(20.2 \%)$ & II (9.6\%) & & $26(21.7 \%)$ & $13(10.8 \%)$ & \\
\hline Circular movement (A) & $69(60.5 \%)$ & $83(72.8 \%)$ & & $53(44.2 \%)$ & $87(72.5 \%)$ & \\
\hline I do not know & $7(6.14 \%)$ & $6(5.26 \%)$ & & $17(14.2 \%)$ & $8(6.67 \%)$ & \\
\hline \multicolumn{7}{|l|}{ What type of toothpaste do you use? } \\
\hline I do not know & $61(53.5 \%)$ & $48(42.1 \%)$ & 0.08 & $85(70.8 \%)$ & $21(17.5 \%)$ & $<0.00 I^{*}$ \\
\hline Toothpaste with fluoride (A) & $49(43.0 \%)$ & $62(54.4 \%)$ & & $32(26.7 \%)$ & $96(80.0 \%)$ & \\
\hline Toothpaste without fluoride & $4(3.51 \%)$ & $4(3.51 \%)$ & & $3(2.50 \%)$ & $3(2.50 \%)$ & \\
\hline \multicolumn{7}{|l|}{ Do you floss your teeth? } \\
\hline No & $58(50.9 \%)$ & $37(32.5 \%)$ & $0.04 *$ & $74(61.7 \%)$ & $26(21.7 \%)$ & $<0.00 I^{*}$ \\
\hline Sometimes & $37(32.5 \%)$ & $45(39.5 \%)$ & & $31(25.8 \%)$ & $52(43.3 \%)$ & \\
\hline Yes $(A)$ & $19(16.7 \%)$ & $32(28.1 \%)$ & & $15(12.5 \%)$ & $42(35.0 \%)$ & \\
\hline \multicolumn{7}{|l|}{ How often do you use mouthwash? } \\
\hline Only when prescribed by the doctor & $10(8.7 \%)$ & $39(34.2 \%)$ & $<0.001 *$ & $7(5.8 \%)$ & $49(40.8 \%)$ & $0.014^{*}$ \\
\hline I do not use mouthwash & $57(50.0 \%)$ & $26(22.8 \%)$ & & $74(61.7 \%)$ & $21(17.5 \%)$ & \\
\hline Once per day every 2 weeks (A) & $\mathrm{I}(0.88 \%)$ & $18(15.8 \%)$ & & $8(6.6 \%)$ & $22(18.3 \%)$ & \\
\hline Once a week & $10(8.7 \%)$ & $31(27.2 \%)$ & & $16(13.3 \%)$ & $28(23.3 \%)$ & \\
\hline Once a day & $36(31.6 \%)$ & $0(0.00 \%)$ & & $15(12.5 \%)$ & $0(0.00 \%)$ & \\
\hline \multicolumn{7}{|l|}{ How often do you visit the dentist? } \\
\hline On demand & $83(72.8 \%)$ & $38(33.3 \%)$ & $<0.001 *$ & $96(80.8 \%)$ & $26(21.7 \%)$ & $<0.00 I^{*}$ \\
\hline Once a year & $3(2.6 \%)$ & $4(3.5 \%)$ & & $5(4.1 \%)$ & $19(15.8 \%)$ & \\
\hline Every 6 months $(A)$ & $9(7.9 \%)$ & $35(30.7 \%)$ & & $5(4.1 \%)$ & $61(50.8 \%)$ & \\
\hline Every 3 months & $19(16.7 \%)$ & $37(32.5 \%)$ & & $13(10.8 \%)$ & $14(11.7 \%)$ & \\
\hline
\end{tabular}

Notes: Statistical analysis was performed using the McNemar's test. (A) The correct answer. $* P \leq 0.05$.

lecture group for question number 2 and 3. The opposite was observed for question numbers 1,5 and 6 where participants from lecture group gave more correct answers than those who used the app. No statistically significant differences were found between the two groups for the remaining questions.

Statistical analysis showed that there was no statistically significant interaction between gender and time $(\mathrm{P}>0.05)$ for the frequency of brushing, frequency of changing the toothbrush, frequency of using mouthwash, best brushing technique, type of toothpaste used, and frequency of dental visit (data not shown). However, the frequency of using floss increased to a higher extent in females (16.7\% to $39.9 \%)$ compared to males (11.5\% to $19.8 \%)$ although these differences were statistically significant only at 0.1 level. These non-significant results can be explained by the fact that the percentage of changes was similar across males and females. 


\section{Discussion}

In the current study, the effectiveness of the Brush DJ app, which is listed in the NHS Choices Health Apps Library, was compared with the conventional means of oral hygiene education. The app was found to be equally effective compared to educational lectures in changing oral health knowledge, attitude and behavior. Participants from both groups showed significant improvements in almost all aspects of oral health. The only exception was the frequency of tooth brushing in the app group.

Our results confirm the findings of earlier studies that increased oral health knowledge and awareness has a positive impact on healthy oral hygiene practices. ${ }^{6-10}$ However, it is to be noted that health promotion programs such as oral health education alone may not be sufficient to develop healthy oral hygiene behaviors. ${ }^{20}$ Such programs can temporarily improve oral health behavior and attitude irrespective of the educational approach, ${ }^{21,22}$ still, other potential confounders (eg, socioeconomic condition, family situations, peer and social influences, local customs, cultural values and availability of resources) may adversely hinder the development of healthy oral practices. Hence, there has been a need for well-structured oral health educational interventions that involve psychological and behavior-change strategies and target a broader goal of making an actual change in attitudes, behaviors, intentions, beliefs and lifestyle. ${ }^{23}$

The benefits of using technologies as an educational tool have been highlighted in dental literature. ${ }^{14-18,24}$ Smartphones and other mobile devices may be a valuable tool for health promotion, as they are more readily accepted among young people than traditional means of dental education. ${ }^{16,25,26}$ In fact, in clinical settings, dental education apps have been found to improve patient-provider communication. ${ }^{27}$ Besides, while the conventional dental education programs involve workforce utilization and are difficult to organize, the use of dental education apps may provide an effortless means of delivering health information to a wider audience due to the widespread adoption of mobile devices and their powerful technological advances. ${ }^{12,14,17,25}$ In addition, these apps may not only increase knowledge and awareness about maintaining good oral health but also motivate their users to follow an evidence-based oral hygiene routine. $^{19}$

In this study, a higher trend of correct answers was observed among students who received educational lectures than those who used the app. Our findings can somewhat be considered similar to the findings of a recent randomized controlled trial where the effect of the WhiteTeeth app was examined on oral hygiene behavior in adolescents. ${ }^{13}$ The authors reported that although the mobile app incorporated many behavior change techniques, its effects in changing tooth-brushing frequency and duration were similar to that of usual care. However, the effect of mHealth on school children may also depend on age. In a recently published study on children of 4 to 7 years, Zotti et $\mathrm{al}^{28}$ found mobile apps to be more effective, engaging and fun compared to verbal oral hygiene instructions. The higher trend observed in our study may partly be due to the personalized nature of the educational lectures, as students received individual level oral health education and motivation from a dental professional. It is undeniable that individual-level communication with dentists will have more influence on high school students in making healthcare decisions than an app that attempts to replace a direct patient-provider discussion. ${ }^{27,29}$

On the other hand, oral health education apps appear to be largely less appealing among school students, as children of this age group tend to use mobile apps mostly for entertainment or gaming purposes rather than education. This has been demonstrated in two recent studies where the authors found that most of the currently available oral hygiene apps lack user engagement and need improvement in terms of aesthetics and information accuracy. ${ }^{30,31}$ Strategies that can be implemented to improve user engagement with an app include ease of use, attractive user interface, unique smartphone features (eg, real-time visualized brushing instructions), and tailored design and information. ${ }^{13,15,30,31}$ Nevertheless, as suggested by several recently published studies, ${ }^{17,18,28}$ incorporating mobile apps with a standard oral hygiene program may be a more plausible approach for oral health promotion among adolescents than educational lectures alone such as via distance motivational tutoring by a dentist or an educator.

Another possible reason for the lower trend in the app group might be the differences in correct answers between the two groups at baseline. In fact, the app group participants gave significantly higher correct answers than the lecture group for four of the eight questions repeated in the follow-up survey. Nevertheless, the actual reason for this needs further investigation, as the findings could help improve the app and allow inclusion of effective behavior change techniques. 
In our analysis, it appeared that the Brush DJ app needs some improvements in several aspects. While the app primarily aims to motivate users to brush twice a day and for 2 minutes by playing music, statistical analysis of baseline and follow-up data revealed no change in twice daily tooth brushing of app users. In addition, less than $40 \%$ reported brushing their teeth for 2 minutes. In contrast, a statistically significant change was noted in these two aspects of oral hygiene routine in lecture group participants. Moreover, our findings also sharply contrasted with the results of Underwood et $\mathrm{al}^{19}$ where around $77 \%$ of app users reported brushing at least twice a day and $88 \%$ reported being motivated by the app to brush their teeth for longer. These differences could be in part attributed to the non-user-friendly nature of the app, as around $22 \%$ of app users were not fully satisfied with the way of teaching and $18 \%$ reported encountering difficulty in using the app. In this investigation, however, these app users were not asked why. This needs to be investigated in future studies to help improve the app.

There are several limitations to this study. Firstly, the results of this study cannot be generalized to Saudi young population due to the small sample size and recruitment of participants from two specified schools in Jeddah City, Saudi Arabia. Secondly, all information collected in this survey is based on self-reported data of participants. This may have introduced bias due to the chances of falsepositive responses from participants. Hence, the data presented on oral health knowledge, attitude and behaviors could be an under- or over-estimation. Thirdly, due to logistical constraints, no dental assessment was done to assess the actual oral health status of study participants. This could have allowed for an objective assessment of responses by the participants. Other limitations of this study include the cross-sectional design, no adjustment for potential confounders such as socioeconomic condition and social factors, and short time period between baseline and follow-up survey.

Further research is warranted with a randomized control design to obtain more meaningful outcomes. Future studies should also adjust for potential variables and include objective assessment of oral health status before and after the intervention.

\section{Conclusion}

The use of mobile apps in dentistry may become an alternative to the conventional method of dental education; however, they cannot be a substitute for a direct patient-provider communication. These apps may at best act as a pedagogical enhancing tool in dental education. Considering this limitation, such educational apps need to be built through an interdisciplinary collaboration among dentists and other professionals (eg, teachers and psychologists). The developers of these applications also need to involve end-users to design and develop the apps in such a manner that they are more practical and user-friendly. Alternatively, if these apps include a feature like distance education or counseling by a doctor or an educator, they can more readily be integrated in the routine dental practice, as this would enable patients to get oral health advice directly from dentists during this COVID-19 pandemic.

\section{Clinical Relevance \\ Scientific Rationale for Study}

The present study was conducted to evaluate the effectiveness of two different oral disease preventive approaches, a mobile application (Brush DJ app) and educational lecture (conventional method), in school children.

\section{Principal Findings}

The use of both the mobile app and educational lecture significantly improved oral health knowledge, attitude and practices among study participants. However, the app was found to be less effective than educational lecture to motivate an evidence-based oral hygiene routine.

\section{Practical Implications}

The Brush DJ app may be a useful tool to improve oral health knowledge, attitude and behavior. However, it needs some improvements. The content and features of the app needs to be more interactive, practical and user-friendly.

\section{Disclosure}

The authors report no conflicts of interest for this work.

\section{References}

1. Vos T, Abajobir AA, Abate KH, et al. Global, regional, and national incidence, prevalence, and years lived with disability for 328 diseases and injuries for 195 countries, 1990-2016: a systematic analysis for the Global Burden of Disease Study 2016. Lancet. 2017;390:1211-1259.

2. Gift HC, Atchison KA. Oral health, health, and health-related quality of life. Med Care. 1995;44:601-608.

3. Petersen PE, Lennon MA. Effective use of fluorides for the prevention of dental caries in the 21 st century: the WHO approach. Community Dent Oral Epidemiol. 2004;32:319-321. doi:10.1111/j.1600-0528. 2004.00175.x 
4. Petersen PE, Ogawa H. Prevention of dental caries through the use of fluoride-the WHO approach. Community Dent Health. 2016;33:66-68.

5. Mullane O, Baez RJ, Jones S, et al. Fluoride and oral health. Community Dent Health. 2016;33:69-99.

6. Hamilton ME, Coulby WM. Oral health knowledge and habits of senior elementary school students. $J$ Public Health Dent. 1991;51:212-219. doi:10.1111/j.1752-7325.1991.tb02217.x

7. De Silva AM, Hegde S, Nwagbara BA, et al. Community-based population-level interventions for promoting child oral health. Cochrane Database Syst Rev. 2016;12:CD009837.

8. Al Subait AA, Alousaimi M, Geeverghese A, Ali A, El Metwally A. Oral health knowledge, attitude and behavior among students of age 10-18 years old attending Jenadriyah festival Riyadh; a crosssectional study. Saudi J Dent Res. 2016;7:45-50. doi:10.1016/j. sjdr.2015.05.001

9. Peltzer K, Pengpid S. Oral health behaviour and social and health factors in university students from 26 low, middle and high income countries. Int J Environ Res Public Health. 2014;11:12247-12260. doi:10.3390/ijerph111212247

10. Angelopoulou M, Kavvadia K, Oulis C, Reppa C. Oral hygiene facilitators and barriers in greek 10 years old schoolchildren. Int J Clin Pediatr Dent. 2015;8(2):87-93. doi:10.5005/jp-journals $-10005-1290$

11. McGrath C, Broder H, Wilson-Genderson M. Assessing the impact of oral health on the life quality of children: implications for research and practice. Community Dent Oral Epidemiol. 2004;32:81-85. doi:10.1111/j.1600-0528.2004.00149.x

12. Steinhubl SR, Muse ED, Topol EJ. The emerging field of mobile health. Sci Transl Med. 2015;7:283rv3. doi:10.1126/scitranslmed. aaa3487

13. Scheerman JFM, van Meijel B, van Empelen P, et al. The effect of using a mobile application ("WhiteTeeth") on improving oral hygiene: a randomized controlled trial. Int $J$ Dent Hyg. 2020;18:73-83. doi:10.1111/idh.12415

14. Sharif MO, Newton T, Cunningham SJ. A systematic review to assess interventions delivered by mobile phones in improving adherence to oral hygiene advice for children and adolescents. $\mathrm{Br}$ Dent $\mathrm{J}$. 2019;227:375-382. doi:10.1038/s41415-019-0660-5

15. Shida H, Okabayashi S, Yoshioka M, et al. Effectiveness of a digital device providing real-time visualized tooth brushing instructions: a randomized controlled trial. PLoS One. 2020;15:e0235194. doi:10.1371/journal.pone.0235194

16. Toniazzo MP, Nodari D, Muniz FW, Weidlich P. Effect of mHealth in improving oral hygiene: a systematic review with meta-analysis. J Clin Periodontol. 2019;46:297-309. doi:10.1111/jcpe.13083

17. Zotti F, Dalessandri D, Salgarello S, et al. Usefulness of an app in improving oral hygiene compliance in adolescent orthodontic patients. Angle Orthod. 2016;86:101-107. doi:10.2319/010915-19.1
18. Zotti F, Zotti R, Albanese M, Nocini PF, Paganelli C. Implementing post-orthodontic compliance among adolescents wearing removable retainers through Whatsapp: a pilot study. Patient Prefer Adherence. 2019;13:609-615. doi:10.2147/PPA.S200822

19. Underwood B, Birdsall J, Kay E. The use of a mobile app to motivate evidence-based oral hygiene behaviour. Br Dent J. 2015;219:E2. doi:10.1038/sj.bdj.2015.660

20. Blaggana A, Grover V, Anjali AK, et al. Oral health knowledge, attitudes and practice behaviour among secondary school children in Chandigarh. J Clin Diagn Res. 2016;10:ZC01-ZC06.

21. Halawany HS, Al Badr A, Al Sadhan S, et al. Effectiveness of oral health education intervention among female primary school children in Riyadh, Saudi Arabia. Saudi Dent J. 2018;30:190-196. doi:10.1016/j.sdentj.2018.04.001

22. Angelopoulou MV, Kavvadia K, Taoufik K, Oulis CJ. Comparative clinical study testing the effectiveness of school based oral health education using experiential learning or traditional lecturing in 10 year-old children. BMC Oral Health. 2015;15:51. doi:10.1186/ s12903-015-0036-4

23. Habbu SG, Krishnappa P. Effectiveness of oral health education in children-a systematic review of current evidence (2005-2011). Int Dent J. 2015;65:57-64. doi:10.1111/idj.12137

24. Ozdalga E, Ozdalga A, Ahuja N. The smartphone in medicine: a review of current and potential use among physicians and students. J Med Internet Res. 2012;14:e128. doi:10.2196/jmir.1994

25. Klasnja P, Pratt W. Healthcare in the pocket: mapping the space of mobile-phone health interventions. $J$ Biomed Inform. 2012;45:184-198. doi:10.1016/j.jbi.2011.08.017

26. Wang J, Wang Y, Wei C, et al. Smartphone interventions for long-term health management of chronic diseases: an integrative review. Telemed J E Health. 2014;20:570-583. doi:10.1089/ tmj.2013.0243

27. Bohn CE, McQuistan MR, McKernan SC, Askelson NM. Preferences related to the use of mobile apps as dental patient educational aids: a pilot study. J Prosthodont. 2018;27:329-334. doi:10.1111/jopr.12667

28. Zotti F, Pietrobelli A, Malchiodi L, Nocini PF, Albanese M. Apps for oral hygiene in children 4 to 7 years: fun and effectiveness. $J$ Clin Exp Dent. 2019;11(9):e795-e801.

29. Saha S, Beach MS. The impact of patient-centered communication on patients' decision making and evaluations of physicians: a randomized study using video vignettes. Patient Educ Couns. 2011;84:386-392. doi:10.1016/j.pec.2011.04.023

30. Tiffany B, Blasi P, Catz SL, McClure JB. Mobile apps for oral health promotion: content review and heuristic usability analysis. JMIR Mhealth Uhealth. 2018;6:e11432. doi:10.2196/11432

31. Sharif MO, Alkadhimi A. Patient focused oral hygiene apps: an assessment of quality (using MARS) and knowledge content. $\mathrm{Br}$ Dent J. 2019;227:383-386. doi:10.1038/s41415-019-0665-0
Patient Preference and Adherence

\section{Publish your work in this journal}

Patient Preference and Adherence is an international, peer-reviewed, open access journal that focusing on the growing importance of patient preference and adherence throughout the therapeutic continuum. Patient satisfaction, acceptability, quality of life, compliance, persistence and their role in developing new therapeutic modalities and compounds to optimize clinical outcomes for existing disease states are major areas of interest for the journal. This journal has been accepted for indexing on PubMed Central. The manuscript management system is completely online and includes a very quick and fair peer-review system, which is all easy to use. Visit http:// www.dovepress.com/testimonials.php to read real quotes from published authors. 